\title{
Climatic and insolation control on the high-resolution total air content in the NGRIP ice core
}

\author{
Olivier Eicher, Matthias Baumgartner, Adrian Schilt, Jochen Schmitt, Jakob Schwander, Thomas F. Stocker, and \\ Hubertus Fischer
}

Climate and Environmental Physics, Physics Institute and Oeschger Centre for Climate Change Research, University of Bern, 3012 Bern, Switzerland

Correspondence to: Olivier Eicher (eicher@climate.unibe.ch)

Received: 9 October 2015 - Published in Clim. Past Discuss.: 20 November 2015

Revised: 14 April 2016 - Accepted: 9 September 2016 - Published: 14 October 2016

\begin{abstract}
Because the total air content (TAC) of polar ice is directly affected by the atmospheric pressure and temperature, its record in polar ice cores was initially considered as a proxy for past ice sheet elevation changes. However, the Antarctic ice core TAC record is known to also contain an insolation signature, although the underlying physical mechanisms are still a matter of debate. Here we present a highresolution TAC record over the whole North Greenland Ice Core Project ice core, covering the last 120000 years, which independently supports an insolation signature in Greenland. Wavelet analysis reveals a clear precession and obliquity signal similar to previous findings on Antarctic TAC, with a different insolation history. In our high-resolution record we also find a decrease of $4-6 \%\left(4-5 \mathrm{~mL} \mathrm{~kg}^{-1}\right)$ in TAC as a response to Dansgaard-Oeschger events (DO events). TAC starts to decrease in parallel to increasing Greenland surface temperature and slightly before $\mathrm{CH}_{4}$ reacts to the warming but also shows a two-step decline that lasts for several centuries into the warm interstadial. The TAC response is larger than expected considering only changes in air density by local temperature and atmospheric pressure as a driver, pointing to a transient firnification response caused by the accumulation-induced increase in the load on the firn at bubble close-off, while temperature changes deeper in the firn are still small.
\end{abstract}

\section{Introduction}

The total air content (TAC) in ice cores from polar regions is one of the many parameters that inform us about past environmental conditions. TAC was initially developed to pro- vide robust information about the past surface elevation of ice sheets (Lorius et al., 1968; Raynaud and Lorius, 1973), due to its pressure and, thus, altitude dependence. However, consecutive studies showed that the densification and bubble close-off processes have an even larger influence on the pore volume enclosed in polar ice and, thus, on TAC. We suggest that air enclosure is primarily dependent on two competing processes during densification and bubble close-off. On the one hand increasing ice deformation (creep) with depth leads to expulsion of air and therefore a reduction of the pore space. On the other hand water vapor transport tries to minimize surface free energy of the pore surfaces, enlarging pores and keeping the pore space open against the closure supported by creep. Both processes intensify with increasing temperature. To date, no established theory exists that quantitatively describes the temporal evolution of densification and bubble enclosure of polar firn columns to produce the observed TAC changes in ice cores. However, an empirical relationship with temperature for steady-state firnification conditions exists based on TAC and firn air observations. Raynaud and Lebel (1979) discovered an empirical relationship of pore volume at bubble close-off and snow temperature in the Camp Century (Greenland) ice core, owing to changes in the densification process at equilibrium conditions. Martinerie et al. (1992) confirmed this positive correlation, mainly in Antarctic but also in alpine and Greenland ice cores in late Holocene snow. Krinner et al. (2000) show that interpreting TAC as an elevation proxy is also limited by secular variations in surface pressure as well as by porosity and temperature changes. 
More recently Raynaud et al. (2007), Parrenin et al. (2007) and Lipenkov et al. (2011) reported an apparent anticorrelated local summer insolation imprint in TAC and used it to constrain the timescale of Antarctic ice core records. This orbital synchronization is further supported by variations in the $\mathrm{O}_{2} / \mathrm{N}_{2}$ ratio, which is also correlated with summer insolation (Bender, 2002). The latter relation was shown to hold for the Greenland record GISP2 (Greenland Ice Sheet Project) as well (Suwa and Bender, 2008). Further, Suwa and Bender (2008) showed increasing $\mathrm{O}_{2} / \mathrm{N}_{2}$ ratios for DO events in the GISP2 ice core. Local summer insolation changes apparently affect snow surface properties like structure or grain size that remain preserved through firnification down to the pore close-off depth. Grain size in the uppermost $3 \mathrm{~m}$ is influenced (increased) by summer insolation (measurements from EPICA Dronning Maud Land drill site, Antarctica; J. Freitag, personal communication, 2016) but also by daily weather events. Hutterli et al. (2009) state that the total temperature gradient metamorphism (tTGM) influences the physical properties of the snowpack. tTGM is not necessarily synchronous with insolation, leading to a lag between the orbital parameters and the proxies depending on snow structure. Lipenkov et al. (2011) suggest how the summer insolation signal in the firn at Vostok, Antarctica, a low accumulation area, might influence the TAC at bubble closeoff. However, in the light of the observed faster densification of winter layers with higher $\mathrm{Ca}^{2+}$ concentrations in Greenland firn (Hörhold et al., 2012), it is unclear how surface snow structure in Greenland (high-accumulation sites) might survive the recrystallization process in the firn. In view of this ongoing discussion and of the fact that a clear insolation effect has so far only been documented in Antarctic ice cores, an independent validation based on Greenland ice, which has a different insolation history, is of great importance.

In this paper we present a high-resolution TAC record from the North Greenland Ice Core Project (NGRIP) ice core with 1688 new data points from 134 to $3082 \mathrm{~m}$ depth. The aim of this work is twofold: first, to test known influences on TAC, such as the orbital insolation effect observed in Antarctica, for the first time in Greenland; second, to document transient effects on TAC due to rapid temperature changes known as Dansgaard-Oeschger events (DO events). Note that the insolation effects on pore volume represent a signal imprinted on the firn structure during densification and thus are a signal imprinted in the ice matrix. In contrast, variations in TAC due to direct temperature changes, as expected during DO events, reflect changes in air density at bubble close-off and thus are imprinted in the gas record itself.

This paper is organized as follows. Section 2 explains the method to determine TAC and discusses uncertainties. The new NGRIP record of TAC is presented in Sect. 3. In Sect. 4 we investigate the time characteristics of the TAC record and its signature during DO events. Conclusions are given in Sect. 5.

\section{Methods}

Following Martinerie et al. (1992), the TAC (sometimes also denoted $V$ in the literature) results are expressed in $\mathrm{mL} \mathrm{kg}^{-1}$ standard temperature and pressure (STP) and are related to temperature, pore volume and pressure via (Martinerie et al., 1992):

$\mathrm{TAC}=V_{\mathrm{c}} \frac{P_{\mathrm{c}} \cdot T_{0}}{T_{\mathrm{c}} \cdot P_{0}}$,

with $V_{\mathrm{c}}$ being the pore volume, $P_{\mathrm{c}}$ the pressure and $T_{\mathrm{c}}$ the temperature at bubble close-off, $P_{0}$ the standard pressure $(1013 \mathrm{hPa})$, and $T_{0}$ the standard temperature $(273 \mathrm{~K})$.

\subsection{Measurement and calibration}

The TAC data presented here stem from two different instruments with different procedures. Neither method delivers absolute values and had to be calibrated. In the method by Schmitt et al. (2011), the samples were melted after evacuation using infrared radiation. TAC was determined by pressure and temperature measurements of the released air under well-controlled conditions. These data are referred to as vacuum-melt data. Schmitt et al. (2014) gauged their instrument in an intercalibration exercise with the Laboratoire de Glaciologie et Géophysique de l'Environnement (LGGE) in Grenoble on EPICA Dome C (EDC) ice. In short, two time intervals of the EDC ice core, which were previously measured at the LGGE (Raynaud et al., 2007), were remeasured with the vacuum-melt device. Using 54 overlapping samples derived from the LGGE device and 59 samples from the vacuum-melt device constrained the uncertainty of the calibration to $0.5 \mathrm{~mL} \mathrm{~kg}^{-1}$. Using this vacuum-melt technique 62 NGRIP samples of $160 \mathrm{~g}$ were also measured and are presented in this study.

The 1626 other data points were measured as a by-product of $\mathrm{CH}_{4}$ and $\mathrm{N}_{2} \mathrm{O}$ concentration measurements performed in Bern over many years (Flückiger et al., 2004; Schilt et al., 2010; Baumgartner et al., 2012; Schilt et al., 2013; Baumgartner et al., 2014) with a different instrument. The meltwater was refrozen during the gas extraction process; therefore, we refer to this data as melt-refreeze data. More detail on the extraction technique of this data is given in Sect. 2.1.1 and more on the offset correction between different meltrefreeze measurement periods in Sect. 2.1.2. To reach consistent absolute TAC values, we intercalibrated the meltrefreeze data to the vacuum-melt data. In total, 42 of the 62 vacuum-melt data points lie within 250 years of our meltrefreeze data and were used for a nearest-neighbor analysis. For this analysis, each point of the vacuum-melt data was compared with at most the two nearest neighbors of the offset-corrected (see Sect. 2.1.2) NGRIP data in each time direction if they were not more than 70 (250) years apart from each other. The mean difference between the two methods was $-0.7 \pm 2.0 \mathrm{~mL} \mathrm{~kg}^{-1}\left(-0.53 \pm 2.1 \mathrm{~mL} \mathrm{~kg}^{-1}\right)$. Ac- 
cordingly, the vacuum-melt data and the melt-refreeze data match within error and were therefore not corrected.

\subsubsection{Extraction technique for the melt-refreeze data}

The melt-refreeze data of 2010, 2011 and 2012, in total 1339 data points, were measured as a by-product of $\mathrm{CH}_{4}$ and $\mathrm{N}_{2} \mathrm{O}$ concentration measurements. To extract the air from the ice samples, the samples are melted in an evacuated vessel. We then refreeze the meltwater slowly from below to expel dissolved gases (see, e.g., Flückiger et al., 2004). The extracted gas is then expanded into the sampling loop, $V_{2}$ (Fig. 1). In the apparatus the mole number of extracted gas $n$ is split between two different volumes, $V_{1}$ and $V_{2}$, and therefore using the ideal gas law and the gas constant $R$, we define

$\mathrm{TAC}=\frac{V_{0}}{m}=\frac{n \cdot R \cdot T_{0}}{m \cdot p_{0}}=\frac{R \cdot T_{0}}{m \cdot p_{0}} \cdot\left(n_{1}+n_{2}\right)$.

In the sample extraction device, we consider three volumes (Fig. 1), the head space over the ice sample $V_{\mathrm{h}}$, the tube volume $V_{t}$ and the expansion volume $V_{2}$. We combine $V_{\mathrm{h}}$ and $V_{t}$ to $V_{1}=V_{\mathrm{h}}+V_{t}$. The mole fractions $n_{1}$ and $n_{2}$ in Eq. (2) refer to the volumes $V_{1}$ and $V_{2}$, respectively. $V_{\mathrm{h}}$ is dependent on the size of each individual vessel and on the volume of refrozen meltwater in the vessel, so $V_{1}$ is corrected for the small vessel-specific differences and assuming an ice density of $\rho_{\text {ice }}=917 \mathrm{~kg} \mathrm{~m}^{-3}$. The temperature in the headspace $V_{\mathrm{h}}$ and $V_{\mathrm{t}}$ is not homogeneous, since $V_{\mathrm{h}}$ is cooled below the freezing point, while the tubing $V_{t}$ is exposed to ambient, stabilized lab temperature. $T_{1}$ is therefore close to the freezing point but could not be measured directly. Instead it is determined to be $275.15 \mathrm{~K}$ on average through a calibration with NEEM ice and LGGE data, as described in the supplementary information of NEEM community members (2013). The temperature $T_{2}$ in the sampling loop is held constant at $-60 \pm 0.5^{\circ} \mathrm{C}$. The expanded gas stabilizes in the volume $V_{1}+V_{2}$ at the expansion pressure $p_{\text {exp }}$, measured with the pressure gauge denoted $P$ in Fig. 1. With

$p_{\exp }=\frac{n_{1} \cdot R \cdot T_{1}}{V_{1}}=\frac{n_{2} \cdot R \cdot T_{2}}{V_{2}}$.

Substituting this in Eq. (2) we get

$\mathrm{TAC}=\frac{T_{0} \cdot p_{\exp }}{m \cdot p_{0}} \cdot\left(\frac{V_{1}}{T_{1}}+\frac{V_{2}}{T_{2}}\right)$.

Note that the parameter $T_{1}$ may slightly vary with lab temperature and also with different extraction vessels. Assuming errors of $0.5^{\circ} \mathrm{C}$ for $T_{1}$ and $T_{2}, 0.2 \mathrm{~mL}$ for $V_{1}$ and $V_{2}, 0.01 \mathrm{~g}$ for the mass $m$ of the ice sample (Baumgartner, 2013), and $50 \mathrm{~Pa}$ for $p_{\exp }$ (at an average $p_{\exp }$ of $4000 \mathrm{~Pa}$ for a sample), the resulting uncertainty in TAC is $1.3 \mathrm{~mL} \mathrm{~kg}^{-1}$, which corresponds to about $1.5 \%$ of the TAC value in NGRIP ice.

The error used for the 2010, 2011 and 2012 data in the plots and for the interpretation was also determined by repro-

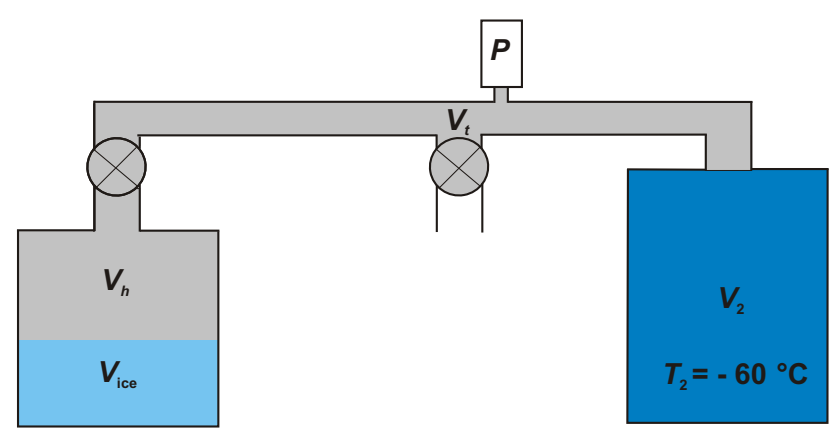

Figure 1. Scheme of the volumes involved in the TAC measurements. The gas from the refrozen meltwater in the vessel on the left is confined in the headspace volume $V_{\mathrm{h}}$. It is then expanded in the volume $V_{\exp }=V_{1}+V_{2}=V_{\mathrm{h}}+V_{\mathrm{t}}+V_{2}$. The temperature $T_{2}$ in $V_{2}$ is held at $-60^{\circ} \mathrm{C}$.

ducibility measurements. Five adjacent samples were measured at 15 depth levels. At each of the 15 depths, we measured TAC randomly distributed over the different extraction vessels and duration of the measurement series. The pooled standard deviation of the residuals of the 75 samples is $2.2 \pm 0.8 \mathrm{~mL} \mathrm{~kg}^{-1}$ (about $2.5 \%$ of the TAC value in NGRIP ice), which is higher than the calculated analytical error of $1.3 \mathrm{~mL} \mathrm{~kg}^{-1}$. This is expected due to natural variations of TAC in the ice along the $25 \mathrm{~cm}$ of ice core used for the reproducibility measurements (see also Sect. 3 below) and variations in the number and size of the air bubbles opened on the sides of the ice cube during cutting. In order to minimize the latter effect, we cut all samples the same way, in pieces of $\sim 40 \mathrm{~g}$.

The whole TAC dataset has a mean value of $93.4 \mathrm{~mL} \mathrm{~kg}^{-1}$ with a standard deviation of $4.5 \mathrm{~mL} \mathrm{~kg}^{-1}$. The measured TAC data show notable high-frequency variability which is much larger than the derived analytical error of $1.3 \mathrm{~mL} \mathrm{~kg}^{-1}$ (see Fig. 3). We infer that a considerable part of the scattering in neighboring samples seems to result from the small-scale variability of the TAC signal in the ice itself. One option to verify this is to check whether the scattering diminishes with depth and therefore decreasing annual layer thickness, as described in Baumgartner et al. (2014). If the scattering is a signal in the ice itself, the standard deviation of the values in the five adjacent reproducibility samples should get smaller with increasing depth, since high-frequency variations will be smoothed by the increasing time interval per sample due to layer thinning with depth. In Fig. 3 the standard deviation over the reproducibility measurements is plotted vs. depth. There is a clear trend to lower scattering with depth (although not with a high correlation coefficient), indicating that part of the scatter is embedded in the ice itself. Martinerie et al. (1992) found seasonal peaks with up to 10-25\% amplitude in TAC, so we can assume most of the scattering to be caused by seasonal cycles or interannual variability. If we do so, we average over more cycles with an increasing age interval cov- 


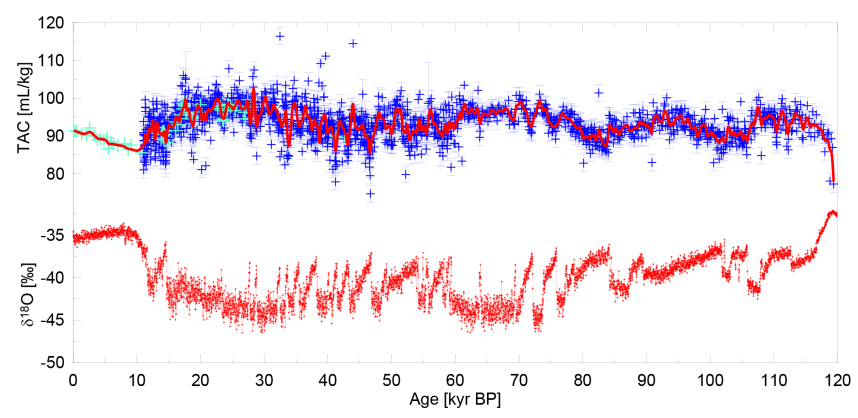

Figure 2. The NGRIP TAC record of this study on the AICC2012 gas age scale (Veres et al., 2013), using two different methods. Blue: the melt-refreeze data; turquoise: the vacuum-melt TAC. The red line represents a spline with a 750-year cutoff period, according to Enting (1987). At the bottom, the $\delta^{18} \mathrm{O}_{\text {ice }}$ for the NGRIP ice core (NGRIP Project Members, 2004) is given.
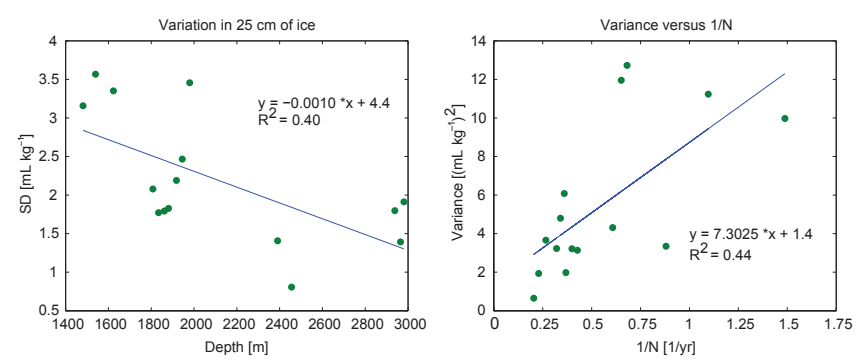

Figure 3. Left: standard deviation of reproducibility measurements in the TAC dependent on depth. Each point represents the mean over five adjacent samples. As expected, the variations get smaller with the smoothing due to thinner annual layers. Right: the variation of the reproducibility measurements vs. $1 / N$, where $N$ is the number of annual cycles in the sample.

ered in the $25 \mathrm{~cm}$ of the adjacent reproducibility samples. The measured variation should therefore decrease with $1 / N, N$ being the number of years contained in one sample, and the five samples in each $25 \mathrm{~cm}$ interval provide us with information on the analytical error according to

$\sigma_{\text {measured }}^{2}=\frac{\sigma_{\text {ice }}^{2}}{N}+\sigma_{\text {analytical }}^{2}$.

If $N$ approaches infinity we get an independent estimate of our analytical error. In Fig. 3 in the right panel we display the variation in the reproducibility samples vs. $1 / N$ with the best linear fit. We get a $y$ intersect (corresponding to $N=\infty$ ) of $1.4 \mathrm{~mL}^{2} \mathrm{~kg}^{-2}$. If the square root is taken, this independent estimate leads to an analytical error of $1.2 \mathrm{~mL} \mathrm{~kg}^{-1}$, very close to the $1.3 \mathrm{~mL} \mathrm{~kg}^{-1}$ we calculated in Sect. 2.1.1.

Most of our TAC data (years 2010-2012) were measured using the above described method, while data obtained between 2002 and 2004, 287 samples in total, were measured with a slightly different procedure, as described in Flückiger et al. (2004). The main difference is that at that time the evacuation step after loading the ice into the vessel lasted for $2 \mathrm{~h}$
Table 1. List of abbreviations in the order in which they are first used.

\begin{tabular}{ll}
\hline Abbreviation(s) & Denotation \\
\hline TAC & Total air content (in literature also called $V)$ \\
$V_{\mathrm{c}}, P_{\mathrm{c}}, T_{\mathrm{c}}$ & Volume, pressure and temperature at close-off \\
$P_{0}, T_{0}$ & Standard pressure and temperature \\
$m$ & Mass of the ice sample \\
$n$ & Mole number \\
$V_{2}$ & Volume of the sampling loop \\
$V_{1}, V_{\mathrm{h}}, V_{\mathrm{t}}$ & Volumes in the apparatus, with $V_{1}=V_{\mathrm{h}}+V_{\mathrm{t}}$ \\
$T_{1}, T_{2}$ & and h for headspace, t for transition \\
& The temperature in the abovementioned volumes \\
ISI, sISI & $V_{1}$ and $V_{2}$ \\
$V_{\mathrm{cr}}$ & Integrated summer insolation, standardized ISI \\
TAC & Non-thermal residual term of the pore volume \\
$V_{\mathrm{cr}}^{*}$ & $-\frac{\text { TAC-TAC }}{\sigma(\mathrm{TAC})}$ \\
$V_{\mathrm{mol}}$ & $-\frac{V_{\mathrm{cr}}-V_{\mathrm{cr}}}{\sigma\left(V_{\mathrm{cr}}\right)}$ \\
\hline
\end{tabular}

instead of about $30 \mathrm{~min}$, and the released air was expanded three times in sequence into a smaller, unchilled sampling loop for analysis. For those measurements the TAC was determined three times per sample and the analytical error of TAC was estimated as the standard deviation of the three measurements, leading to individual error bars for each data point with an average error of $2.86 \mathrm{~mL} \mathrm{~kg}^{-1}$.

\subsubsection{Offset correction in the melt-refreeze data}

The 2002-2004 and 2010-2012 data are slightly offset from each other, so a method to intercalibrate the two data sets was developed. Also, between the measurement periods of 2010, 2011 and 2012, minor changes in the instrument could lead to small offsets which have to be accounted for. Data pairs of corresponding sample depths in the NGRIP ice core from the different measuring periods were identified, the measuring period of 2012 was taken as a reference. Reference data points are compared with interpolated values of the other dataset. Only the data from 2010 could not be compared directly to 2012 because they cover different sections of the ice core, and hence the 2010 data set was compared to the 2011 data. The mean of the offset values is displayed in Table 1 together with its standard error. The age differences to the closest points of the reference values are also shown in Table 2, with the interpolations providing better results if the data points are closer to each other, as expected from the natural variability of TAC in the ice. Based on this comparison, the data from 2002 were shifted by $3.4 \mathrm{~mL} \mathrm{~kg}^{-1}$, those from 2004 by $6.1 \mathrm{~mL} \mathrm{~kg}^{-1}$ and those from 2011 by $-2 \mathrm{~mL} \mathrm{~kg}^{-1}$. The 2010 data are not significantly different $\left(1.2 \pm 1.4 \mathrm{~mL} \mathrm{~kg}^{-1}\right)$ from 2012 , so no correction was made. This corrected melt-refreeze data set was used to compare with the vacuum-melt data and showed no significant offset, as described in Sect. 2.1. 


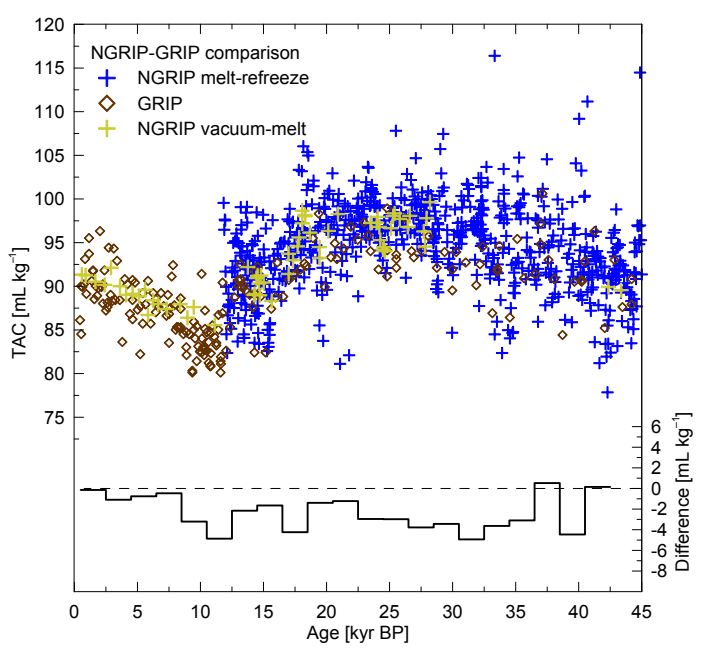

Figure 4. GRIP TAC data (Raynaud et al., 1997) in brown, vacuummelt TAC data in yellow and melt-refreeze TAC data in blue. All data on the synchronized ice age scale for GRIP and NGRIP are according to Seierstad et al. (2014). The black curve at the bottom represents the difference between GRIP and NGRIP TAC data in 2 kyr intervals.

\section{The NGRIP TAC record}

Our new NGRIP record contains 1688 TAC data points and is shown in Fig. 2 on the AICC2012 gas age scale (Veres et al., 2013), along with $\delta^{18} \mathrm{O}_{\text {ice }}$. The depth range is 133.81 to $3082.23 \mathrm{~m}$, which corresponds to 294 to 119555 years in gas age on the AICC2012 timescale.

\subsection{Comparison with GRIP TAC}

Raynaud et al. (1997) presented a lower-resolution Greenland TAC data set from the GRIP ice core. GRIP is located $316 \mathrm{~km}$ south-southeast of NGRIP, at an altitude of $3232 \mathrm{~m}$, compared to $2919 \mathrm{~m}$ at NGRIP (Dahl-Jensen et al., 1997). Today there is essentially no temperature difference between NGRIP and GRIP as the altitude effect is compensated for by the higher latitude of the former. Therefore, and because insolation differences are insignificant between the two sites due to their geographic proximity, we do not expect any difference either in pore volume $V_{\mathrm{c}}$ (Martinerie et al. (1992). Accordingly, assuming the temperature consistency did also not change in the past, the only factor influencing the TAC difference between the two sites is altitude (and possibly wind (Martinerie et al., 1994), which is ignored here). The GRIP data mainly cover the Holocene with measurements back to $40.6 \mathrm{ka}$ BP. In Fig. 4 we show the TAC from Raynaud et al. (1997), along with our two TAC records (meltrefreeze and vacuum-melt) in the time interval 0.2 to $45 \mathrm{ka}$ $\mathrm{BP}$ on gas age. The GRIP and NGRIP data are given on a synchronized ice age scale for the Greenland records (Seierstad et al., 2014). The data show good agreement; the GRIP
Table 2. Table with the offsets between the data from different measuring periods. The second number in the intervals column is the reference period. Offset values are the median of all data points compared. The given error is the standard error. $n$ is the number of points compared. Av. age offset denotes the average difference to the closer endpoint of the interpolation interval. The 2010 data could not be compared directly to 2012, so the offset values in the table are calculated from the other offsets.

\begin{tabular}{lrcc}
\hline $\begin{array}{l}\text { Intervals } \\
(\mathrm{yr})\end{array}$ & $\begin{array}{r}\text { Offset } \\
\left(\mathrm{mL} \mathrm{kg}^{-1}\right)\end{array}$ & $n$ & $\begin{array}{c}\text { Av. age } \\
\text { (offset } \mathrm{yr})\end{array}$ \\
\hline 2004 and 2012 & $-6.1 \pm 0.6$ & 33 & 196 \\
2002 and 2012 & $-3.4 \pm 2.1$ & 24 & 348 \\
2010 and 2011 & $3.16 \pm 0.9$ & 37 & 47 \\
2012 and 2011 & $-2.0 \pm 1.1$ & 24 & 344 \\
2010 and 2012 & $1.2 \pm 1.4$ & - & - \\
\hline
\end{tabular}

TAC air content is on average slightly lower. To quantify the difference, each point from GRIP was compared with at most the two nearest neighbors of the NGRIP data in each time direction if they lay within 250 years of the GRIP data point. Up to $11.5 \mathrm{ka}$ (Holocene) GRIP data were only compared to vacuum-melt data since no melt-refreeze data were available. The Holocene GRIP TAC is about $1.7 \pm 0.3 \mathrm{~mL} \mathrm{~kg}^{-1}$ lower than NGRIP, and glacial GRIP in the interval 11.5 to $45 \mathrm{ka}$ is $2.4 \pm 0.3 \mathrm{~mL} \mathrm{~kg}^{-1}$ lower, where the error is the standard error of the mean. This is generally in line with the expectations: a higher altitude at the deposition site should lead to lower TAC. Our results are different by $1 \sigma$, which is almost a non-significant difference, but they leave room for small relative altitude changes from the Last Glacial Maximum (LGM) to the Holocene between the two sites, although other studies (e.g. NGRIP Project Members, 2004) state that the relative altitude changes are believed to be small. Assuming a mean annual temperature of $-46^{\circ} \mathrm{C}$ $\left(-31.5^{\circ} \mathrm{C}\right.$ ) for stadial (Holocene) conditions (Kindler et al., 2014) at NGRIP and using the barometric formula leads to a pressure-elevation gradient of $\delta P / \delta Z=10.5 \mathrm{hPa} / 100 \mathrm{~m}$ $(9.9 \mathrm{hPa} / 100 \mathrm{~m})$. Ignoring temperature, pore volume and upstream correction, Eq. (1) gives an expected TAC difference of $4.2 \mathrm{~mL} \mathrm{~kg}^{-1}\left(4 \mathrm{~mL} \mathrm{~kg}^{-1}\right)$ at an average of $90 \mathrm{~mL} \mathrm{~kg}^{-1}$ and NGRIP bubble close-off pressure of $699 \mathrm{hPa}$ (K. Steffen, University of Colorado, Boulder, personal communication, 2016). This is more than what we observe in our data. Moreover, in reality the pressure-elevation gradient could be larger ( 11 to $15 \mathrm{hPa} / 100 \mathrm{~m}$ ), as automatic weather stations located in the GRIP area suggest (Raynaud et al., 1997). Accordingly, we cannot quantitatively explain the absolute TAC difference between the two sites and therefore also refrain from interpreting the relative change in TAC difference between the sites from the LGM to the Holocene. 


\section{Discussion}

\subsection{Low-frequency variations in TAC}

TAC in Antarctica is known to show an anti-correlation with the integrated local summer insolation (ISI) as shown by Raynaud et al. (2007) for approximately the last 400000 years in the EPICA Dome C record. We define ISI as

$\mathrm{ISI}=\sum_{i=1}^{365} w_{\mathrm{i}} \cdot \theta\left(w_{\mathrm{i}}-w_{0}\right)$

where $w_{\mathrm{i}}$ is the daily insolation in $\mathrm{W} \mathrm{m}^{-2}, \theta$ is the Heaviside step function and $w_{0}$ denotes a threshold insolation. This threshold had been defined by tuning the correlation between ISI and TAC. A similar dependency emerges for our Greenland ice core when calculating a local summer insolation for the NGRIP drill site. A maximum correlation between TAC and ISI is found for $w_{0}=390 \mathrm{~W} \mathrm{~m}^{-2}$, compared to $380 \mathrm{~W} \mathrm{~m}^{-2}$ used by Raynaud et al. (2007) for the Antarctic EPICA Dome C (EDC) ice core. The correlation difference between 380 and $390 \mathrm{~W} \mathrm{~m}^{-2}$ is, however, small, and the threshold does not alter the shape of the ISI much.

Martinerie et al. (1992) found an empirical relationship between the pore volume $V_{\mathrm{c}}$ at bubble close-off and the temperature for recent equilibrium densification conditions with

$V_{\mathrm{c}}=0.76 \cdot\left(\frac{\mathrm{mL}}{\mathrm{K} \cdot \mathrm{kg}}\right) \cdot T_{s}-57 \cdot\left(\frac{\mathrm{mL}}{\mathrm{kg}}\right)$,

where $T_{\mathrm{s}}$ is the snow temperature in Kelvin, here assumed to be the same as the temperature at bubble close-off depth, $T_{\mathrm{c}}$, when the firn column is in thermal equilibrium. Like in Raynaud et al. (2007), we defined the non-thermal residual term $V_{\text {cr }}$ as

$V_{\mathrm{cr}}=\mathrm{TAC} \cdot \frac{T_{\mathrm{c}}}{P_{\mathrm{c}}} \cdot \frac{P_{0}}{T_{0}}-V_{\mathrm{c}}\left(T_{\mathrm{s}}\right)$,

where $T_{\mathrm{c}}$ and $P_{\mathrm{c}}$ are the temperature and pressure at bubble close-off depth. For the temperature at bubble close-off we used values by Kindler et al. (2014) which are derived from a heat conduction model and surface temperature variations using the $\delta^{15} \mathrm{~N}$ thermo-diffusion technique (Severinghaus and Brook, 1999; Lang et al., 1999; Kindler et al., 2014), providing data from 10 to $120 \mathrm{ka}$. For the pressure at bubble closeoff, we use a constant value of $699 \mathrm{hPa} . T_{0}$ and $P_{0}$ are the standard temperature $(273 \mathrm{~K})$ and standard atmospheric pressure $(1013 \mathrm{hPa})$, respectively. Analogous to Raynaud et al. (2007) and Lipenkov et al. (2011), we define a standardized version of TAC and $V_{\text {cr }}$ :

$\mathrm{TAC}^{*}=-\frac{\mathrm{TAC}-\overline{\mathrm{TAC}}}{\sigma(\mathrm{TAC})}$

and

$V_{\mathrm{cr}}^{*}=-\frac{V_{\mathrm{cr}}-\overline{V_{\mathrm{cr}}}}{\sigma\left(V_{\mathrm{cr}}\right)}$.

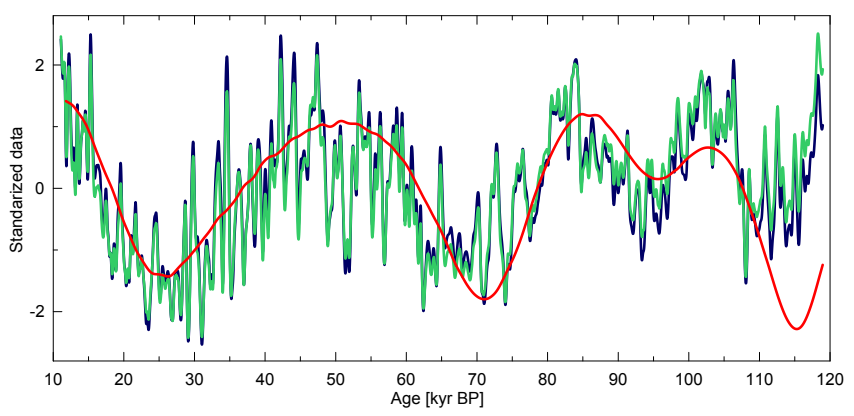

Figure 5. Red: the standardized $75.1^{\circ} \mathrm{N}$ integrated summer insolation sISI on days with more than $390 \mathrm{~W} \mathrm{~m}^{-2}$, splined with a $3 \mathrm{kyr}$ cutoff period. Blue: a standardized spline with a 750-year cutoff of the TAC $^{*}$ record. Green: analogous to Raynaud et al. (2007) the $\mathrm{TAC}^{*}$ data after correcting for the temperature effect on pore volume $V_{\text {cr }}$ (Martinerie et al., 1992). Note that the ice core data are given on the glaciological AICC2012 ice age scale (as solar insolation acts on the snow matrix and therefore on changes in TAC on the ice age scale), while ISI is on the absolute astronomical age scale.

Splines with a 750-year cutoff period (Enting, 1987) through TAC* and $V_{\text {cr }}^{*}$ are shown together with the standardized ISI (sISI), splined with a $3 \mathrm{kyr}$ cutoff period, in Fig. 5.

The $r^{2}$ between TAC $^{*}$ and $V_{\mathrm{cr}}^{*}$ for the spline is 0.95 , so the temperature effect on firnification processes quantified according to Martinerie et al. (1992) is responsible for only $5 \%$ of the TAC variance, in accordance with Raynaud et al. (2007). These authors derived an $r^{2}$ of 0.86 and estimated the temperature-induced TAC variations to $10 \%$ of the total signal. The strong covariance of $\mathrm{TAC}^{*}$ and local insolation for both Greenland and Antarctic ice cores provide independent evidence of an ISI effect on pore volume as the temporal evolution of ISI in both hemispheres differs significantly. As can be seen in Fig. 5, the shape of the sISI is highly covariant with the low-frequency variations of $\mathrm{TAC}^{*}$ and $V_{\mathrm{cr}}^{*}$, while higher-frequency variations seem to correlate with temperature on the ice sheet (see Fig. 2). Note that during the glacial, temperature changes in Greenland are dominated by fast DO events, and a spline through the data filters out some of the variations.

Investigations on the higher frequency variations and TAC relation to climate changes during DO events are discussed in Sect. 4.3.2. In Table 3 the correlations between the sISI, $V_{\mathrm{cr}}^{*}, T_{\mathrm{c}}$ and $\mathrm{TAC}^{*}$ are shown. For the best linear fit we estimate a sensitivity of TAC on the local integrated summer insolation's energy input above $390 \mathrm{~W} \mathrm{~m}^{-2}$ of $-5.7 \times 10^{-9} \mathrm{~mL} \mathrm{~kg}^{-1} \mathrm{~J}^{-1}$ with an $r^{2}$ of 0.3 .

Figure 5 shows that the correlation of ISI and TAC* is absent before about $109 \mathrm{ka}$, i.e. at the glacial inception at the end of the Eemian. Raynaud et al. (2007) associated the $100 \mathrm{kyr}$ cycle in the Antarctic EDC TAC record to pressure differences induced by surface elevation changes. The question arises whether the TAC deviations from the expected insolation effect at the glacial inception in our NGRIP record 

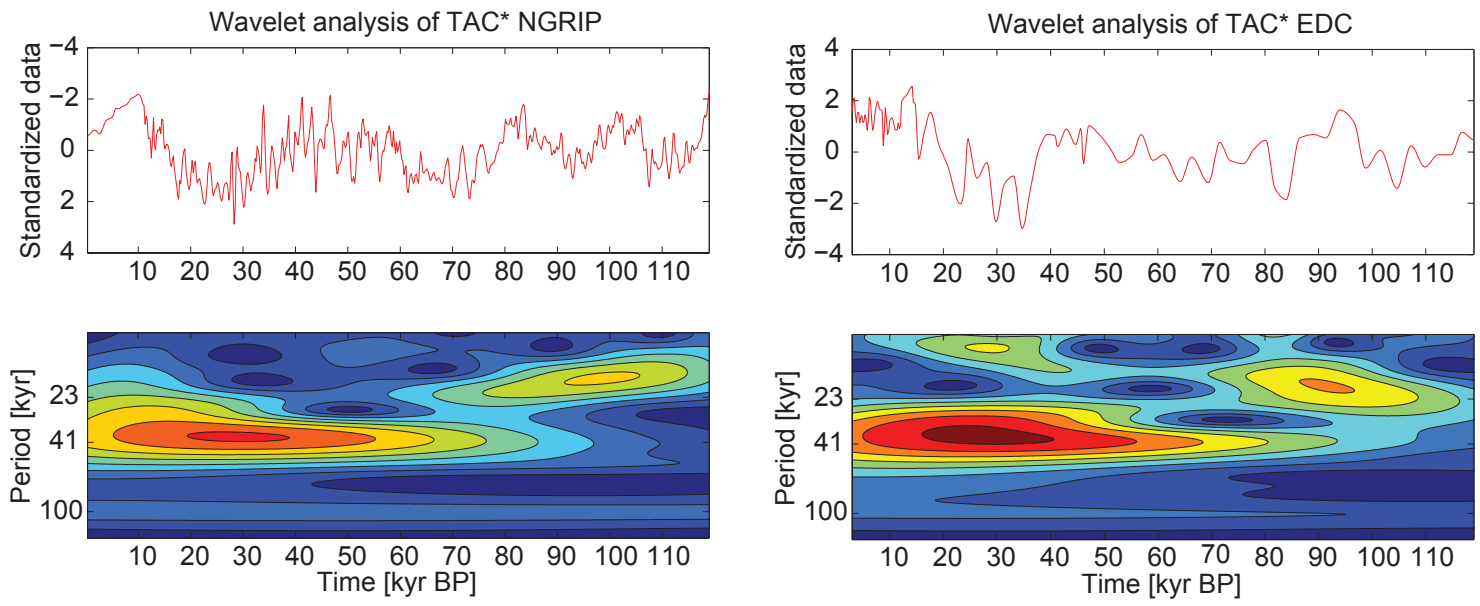

Figure 6. Left: the TAC* ${ }^{*}$ data in red, resampled at an age step of $0.2 \mathrm{kyr}$ and wavelet analysis of this spline. Right: EDC TAC* data (Raynaud et al., 2007), resampled at $0.2 \mathrm{kyr}$ and its wavelet analysis in the same time window.

are also related to ice sheet changes. Models for Greenland ice sheet coverage and surface height in the Eemian show little difference to the present. Using on ice sheet modeling, Born and Nisancioglu (2012) estimate at NGRIP a maximum lowering of $200 \mathrm{~m}$ in the LGM compared to the Holocene. Using the same calculations as in Sect. 3.1, this would account for a TAC change of $2.4 \mathrm{~mL} \mathrm{~kg}^{-1}$, while the observed TAC changes at the very end of the TAC record are in the order of $10 \mathrm{~mL} \mathrm{~kg}^{-1}$.

Note that the correlation breakdown between TAC and ISI before $109 \mathrm{ka}$ mainly results from only two data points (see Fig. 2), at 118.8 and 119.4 ka with very low TAC, and the robustness of the TAC/ISI decoupling can therefore be questioned. If we exclude these two points and correlate the sISI with the TAC* from the top only until $109 \mathrm{ka}, r^{2}$ increases to 0.45 , while the absolute changes in TAC are still larger than expected from altitude changes in models.

It has to be taken into account that the timescale of ISI is absolute, while the AICC2012 age scale used in this study is fundamentally based on an ice-flow model and in particular shows younger ages for the lowest part of the ice core, compared to other timescales (Veres et al., 2013), with an uncertainty of around 5000 years in the lowest part of the ice core. Accordingly, if the older part of the TAC record were shifted to somewhat older ages, the correlation would increase. This would imply that the lowest part of the NGRIP ice core contains not the end of the Eemian but its maximum. The comparison of the NGRIP and NEEM ice and gas records over the Eemian compiled by Landais et al. (2016) shows that such a stretching of the NGRIP record's lowest part would then lead to consistency problems between the NEEM gas records and their Antarctic counterparts, which were used as a template to date the bottommost ice at NEEM. Accordingly, a simple shift of the AICC2012 age scale used for the NGRIP ice core in Fig. 5 seems incompatible with the
Table 3. Table with the squared correlation coefficients between data and calculated parameters TAC* ${ }^{*}$ sISI, $\mathrm{V}_{\mathrm{cr}}^{*}$ and $T_{\mathrm{c}}$.

\begin{tabular}{lcccc}
\hline & TAC $^{*}$ & sISI & $V_{\text {cr }}^{*}$ & $T_{\mathrm{c}}$ \\
\hline TAC $^{*}$ & - & 0.31 & 0.95 & 0.26 \\
SISI & 0.31 & - & 0.24 & 0.01 \\
\hline
\end{tabular}

NEEM ice core. We therefore refrain from providing a new orbitally tuned age scale for the oldest part of the NGRIP record. Instead, other factors than the age scale appear to be responsible for the deviation of TAC from ISI at that time.

\subsection{Spectral analysis}

Following Raynaud et al. (2007), we performed a wavelet analysis on the TAC data (Fig. 6). Between 20 and 70 ka the obliquity effect on TAC is dominant, while for $80-110 \mathrm{ka}$ the precession cycle dominates. This is in agreement with the findings for EDC, displayed in the right panel of Fig. 6. Since both Antarctic EDC and Greenland NGRIP TAC show the same pattern of either obliquity or precession dominance, we performed a cross-wavelet analysis between the TAC and the respective local ISIs. This analysis allows us to find common spectral signals in the time series (see, e.g., Grinsted et al., 2004; Fig. 7).

Our results for NGRIP support the findings by Raynaud et al. (2007) and Lipenkov et al. (2011) on Antarctic TAC being related to ISI. Both records show coherence in the obliquity and precession bands. Antarctic TAC and the $\mathrm{O}_{2} / \mathrm{N}_{2}$ ratio (Lipenkov et al., 2011) were known to contain an ISI signal as was the $\mathrm{O}_{2} / \mathrm{N}_{2}$ ratio in Greenland (Suwa and Bender, 2008). Now we show for the first time that Greenland TAC also contains an ISI signature, similarly to Antarctic TAC records. 

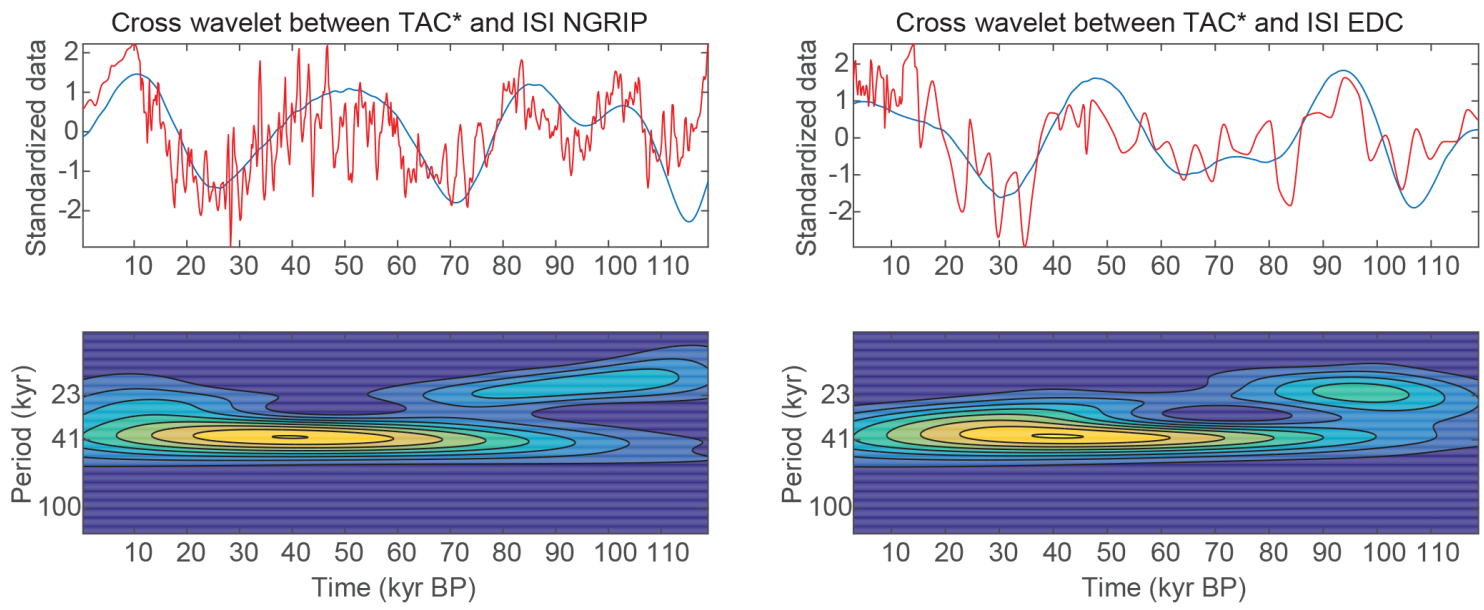

Figure 7. Left: the TAC* data, resampled at $0.2 \mathrm{kyr}$ in red; sISI with a threshold of $390 \mathrm{~W} \mathrm{~m}^{-2}$ in blue, splined with a $3 \mathrm{kyr}$ cutoff period and cross-wavelet analysis thereof. Both records show coherence in the obliquity and precession bands. Right: EDC TAC* (Raynaud et al., 2007) resampled at $0.2 \mathrm{kyr}$, sISI $\left(75.1^{\circ} \mathrm{S}\right)$ with a threshold of $380 \mathrm{~W} \mathrm{~m}^{-2}$ and cross-wavelet analysis of the EDC and sISI.

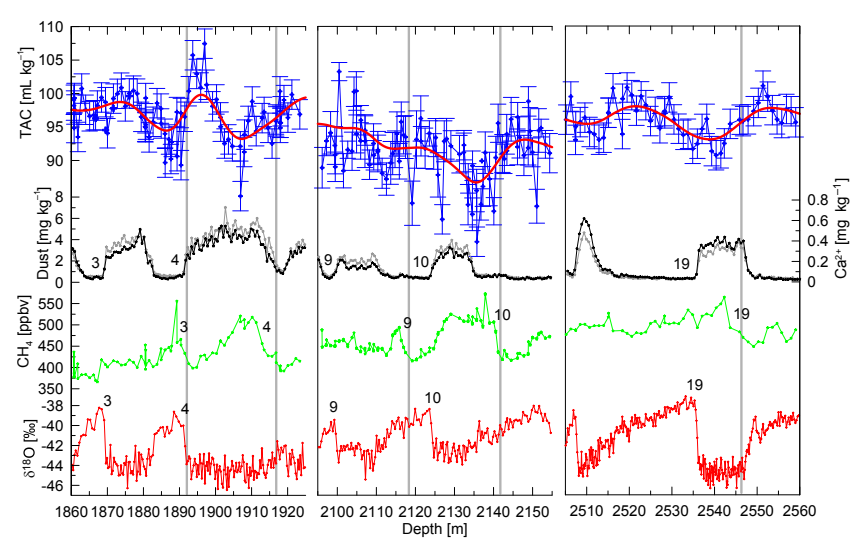

Figure 8. Zoom into DO events 3, 4, 9, 10 and 19 on depth scale. Blue: the TAC, including a spline with a $120 \mathrm{~m}$ cutoff (thick red line). Black: the dust; grey: the $\mathrm{Ca}^{2+}$ concentration (Ruth, 2007). Green: $\mathrm{CH}_{4}$; red: the $\delta^{18} \mathrm{O}_{\text {ice }}$. Grey lines indicate the beginning of the DO events in $\mathrm{CH}_{4}$. More on the timing of TAC changes in Sect. 4.3.2 and in Figs. 9 and 10

\subsection{Higher-frequency TAC variations and DO events}

\subsubsection{Relation to $\mathrm{Ca}^{2+} /$ dust}

Based on recent studies (Freitag et al., 2013), small-scale firn density is known to correlate with $\mathrm{Ca}^{2+}$ concentrations in the ice representative of mineral dust concentration. Accordingly, a firnification effect of dust on pore volume has been proposed (Hörhold et al., 2012), which should be most pronounced for stadial-interstadial variations when dust concentrations in Greenland changed by a factor of about 15 (Fischer et al., 2007). As the TAC is a result of the competing process of densification and water vapor transport/recrystallization, an influence of $\mathrm{Ca}^{2+}$ concentration on
TAC could also be hypothesized. In Fig. 8 the NGRIP TAC, dust and $\mathrm{Ca}^{2+}$ (Ruth, 2007), $\mathrm{CH}_{4}$, and $\delta^{18} \mathrm{O}_{\text {ice }}$ records are shown on the depth scale for selected DO events. No simple relation from TAC with the dust concentration can be observed. Moreover, the TAC variations on their depth scale are not in phase with dust and $\mathrm{Ca}^{2+}$ concentrations, as would be expected from a direct firnification effect of dust concentrations in the ice matrix on pore volume at bubble close-off. Instead, the high-frequency variations in TAC seem to change in parallel with $\mathrm{CH}_{4}$ and therefore on the gas age scale, suggesting a direct influence of temperature on the number of moles of air enclosed in the pore volume during bubble closeoff. We will discuss this anti-correlation in the next section.

\subsubsection{Relation to climate changes during DO events}

The TAC data (Fig. 2) not only show low-frequency variations as discussed in Sect. 4.1 but reveal a strong highfrequency signal. Making use of the unprecedented resolution of our record, we investigate the high-frequency variations and take a closer look at what happens to the TAC during DO events.

The temperature effect (Eq. 7) on the pore volume created during steady-state densification would lead to a very small increase in pore volume with rising temperatures. Using the ideal gas law, we obtain

$$
\begin{aligned}
\mathrm{TAC} & =V_{\mathrm{mol}} \cdot n=V_{\mathrm{mol}} \cdot \frac{P_{\mathrm{c}} \cdot V_{\mathrm{c}}\left(T_{\mathrm{S}}\right)}{R \cdot T_{\mathrm{S}}} \\
& =\frac{P_{\mathrm{c}} \cdot V_{\mathrm{mol}}}{R} \cdot\left(0.76-\frac{57 \mathrm{~K}}{T_{\mathrm{s}}}\right),
\end{aligned}
$$

where $V_{\mathrm{mol}}$ is the volume of one mol at STP, $V_{\mathrm{c}}(T)$ the pore volume at close off, $R$ the gas constant $\left(8.31 \mathrm{~J} \mathrm{~mol}^{-1} \mathrm{~kg}^{-1}\right)$, $T_{\mathrm{S}}$ the snow temperature and $n$ the number of moles of air 

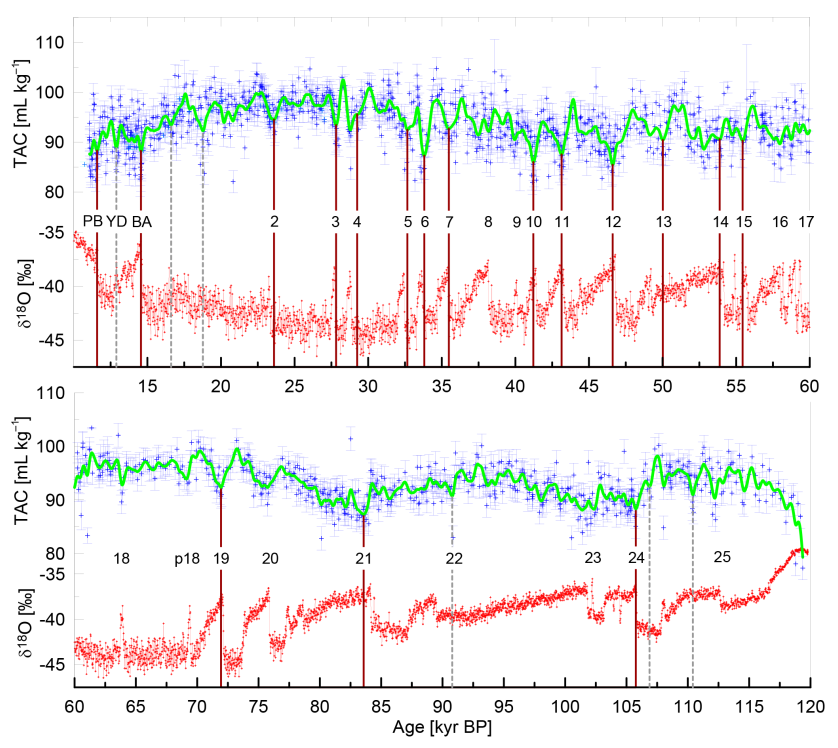

Figure 9. The significant minima in the TAC spline with 750-year cutoff from 10 to $120 \mathrm{ka} \mathrm{BP}$. The measured TAC on AICC2012 gas age scale is blue; the spline is green. Minima marked by ruby lines are considered significant by the algorithm described in the text, while significant minima without a close-by DO event are indicated by grey dashed lines. Red: the $\delta^{18} \mathrm{O}_{\text {ice }}$ on the AICC2012 ice age scale.

enclosed in the bubbles. Therefore, a slight increase in TAC with increasing temperature is expected from the pore volume effect. However, the formula for pore volume changes, derived in Martinerie et al. (1992) based on steady-state Holocene conditions, is most likely not applicable during DO events where a transient change in densification occurs. It is reasonable to assume that the pore volume in the firn does not follow this temperature relationship (Eq. 7) directly at the onsets of DO events. If we assume that the pore volume remains constant during the very first stage of a DO event, the first-order effect of slowly increasing temperatures in the firn would lead to a decrease in TAC, as supported by our data (Fig. 2). To test objectively whether there is a coherent pattern of decreasing TAC at the onset DO events, we developed a method to find significant TAC decreases. To remove noise in the TAC raw data, 1000 Monte Carlo splines (varying the data points randomly within their error before calculating each spline fit) with a cutoff period of 750 years were calculated on the AICC2012 gas age scale, and the mean of the 1000 splines was taken as our best-guess representation of true TAC variations (Monte Carlo average, MCA). This MCA spline is then searched for maxima and minima. A detected minimum is considered significant if the difference between the last maximum and the minimum is larger than 1.5 times the added standard deviation of the spline at both points. The result is shown in Fig. 9. With these criteria and parameters, the routine finds 23 significant minima, of which 17 are related to a DO event in $\delta^{18} \mathrm{O}_{\text {ice }}$. The significant min- ima unassociated with a DO event occur at the onset of the Younger Dryas, two in the LGM and one during DO event 25 . There is another one before DO event 24 , which is due to a wiggle in the spline fit, leading to two significant minima in the descent preceding DO event 24 (see Fig. 9). Using the abovementioned parameters, the routine fails to find significant minima related to DO events $8,9,16-18,20,22,23$ and 25, although for many of these cases a decline in TAC exists, which, however, did not satisfy our significance criterion. For DO events 9, 18 (and the event p18, in Fig. 9 regarded as a precursor event of DO event 18), 20, 23 and 25 , this is due to the threshold of $1.5 \sigma$ being too high, while 16-17 follow each other very closely so the TAC response signal is not visible. For DO event 22 the detected minimum is more than 1000 years before the $\delta^{18} \mathrm{O}_{\text {ice }}$ maximum, so we considered this not to be related to the warming. DO event 22 has a small amplitude in $\delta^{18} \mathrm{O}_{\text {ice }}$ compared to the background and the other DOs; thus, only a small TAC response is expected.

Apparently, TAC shows an anti-correlation not only to ISI but also to rapid DO warmings. Again a comparison to the $\mathrm{O}_{2} / \mathrm{N}_{2}$ ratios is of interest, since Suwa and Bender (2008) found not only a correlation of $\mathrm{O}_{2} / \mathrm{N}_{2}$ to insolation but also a correlation of $\mathrm{O}_{2} / \mathrm{N}_{2}$ ratios with DO warmings. We speculate that both proxies are influenced by the same not yet fully understood firnification processes. The phasing of the TAC compared to the $\delta^{18} \mathrm{O}_{\text {ice }}$ is also of interest. In Table 4 the timing of the TAC minima on the AICC2012 gas age scale and the maxima in the rises of $\delta^{18} \mathrm{O}_{\text {ice }}$ on the AICC2012 ice age scale are shown. On average, the TAC minimum is synchronous with the $\delta^{18} \mathrm{O}_{\text {ice }}$ maximum within the error ( $12 \pm 290$ years) on the AICC2012 age scale. However, as stated by Baumgartner et al. (2014), the AICC2012 gas age scale suffers from inconsistency with the AICC2012 ice age scale for several DO events as gas and ice have been synchronized between different ice cores to some extent independently. This leads to a dephasing of $\mathrm{CH}_{4}$ and $\delta^{18} \mathrm{O}_{\text {ice }}$ records in some cores on the AICC2012 age scale, which is absent in the original age scales, where gas age scale has been determined by adding the gas-age-ice-age difference to the ice age scale. For this reason Kindler et al. (2014) published a new gas age scale for NGRIP, based on the ss09sea06bm (NGRIP Project Members, 2004) ice age scale, defined from 10 to $120 \mathrm{ka}$. Being aware of this inconsistency, we also derived the corresponding $\delta^{18} \mathrm{O}_{\text {ice }}$ maxima on ss09sea06bm ice age and the TAC spline minima on the gas age scale by Kindler et al. (2014). On those age scales the $\delta^{18} \mathrm{O}_{\text {ice }}$ maximum is reached on average $111 \pm 232$ years earlier than the minimum in TAC and only two DO events show the TAC minimum earlier than the $\delta^{18} \mathrm{O}_{\text {ice }}$ maximum. Neglecting DO 13 , the $\delta^{18} \mathrm{O}_{\text {ice }}$ maximum leads TAC by $162 \pm 108$ years $(37 \pm 217$ years on the AICC2012 age scales). Due to the considerable analytical and small-scale scatter of our TAC data, it is difficult to pinpoint the temporal evolution of the TAC and its phase relationship to other climate proxies in the ice core for individual 

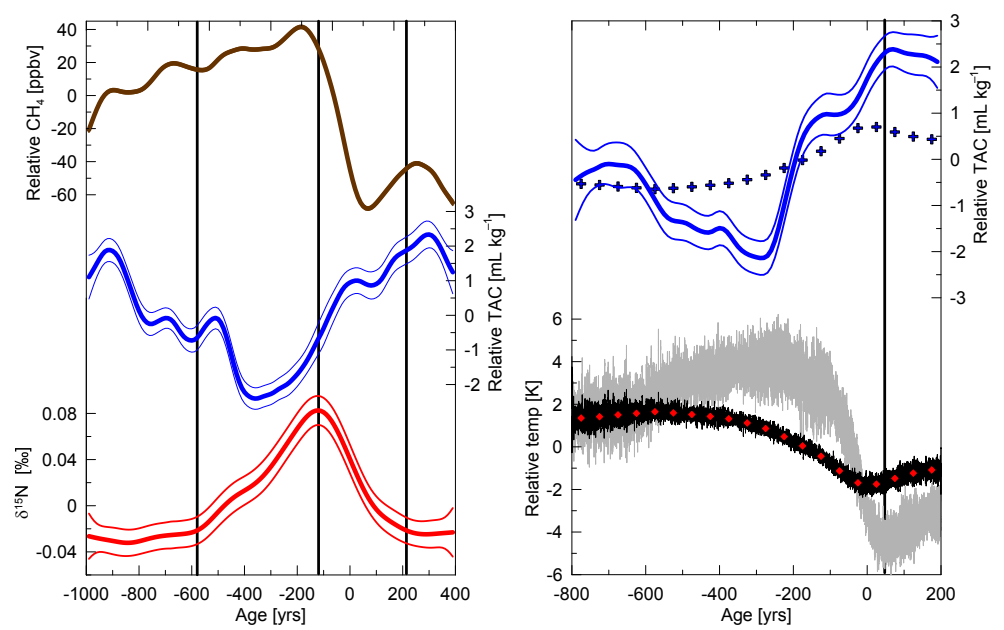

Figure 10. Stacked data over the onsets of all DO events except DO events 2 and 25 (Table 4). Left: red - the stacked $\delta^{15} \mathrm{~N}$ model data (Kindler et al., 2014); blue - the TAC; brown $-\mathrm{CH}_{4}$. Full lines represent the spline; thin lines the $1 \sigma$ error range. Note that the variability in the stacked concentration only refers to the analytical error and not the variability between different DO events. Grey lines indicate the start, the maximum and the end of the $\delta^{15} \mathrm{~N}$ signal. All three are given on AICC2012 gas age scale. Right: running mean over the modeled bubble close-off temperature (Kindler et al., 2014) in black; red squares indicate a 50-year mean. Grey: the modeled surface temperature. Blue crosses represent the calculated TAC values dependent on bubble close-off temperature only. The blue lines represent the measured TAC on ice age scale. Note that the amplitude of the TAC response differs for the left and right plot, since the stack was established on a different age scale and thus not over the same time windows and with different starting points. The grey line indicates the onset of the surface temperature warming.

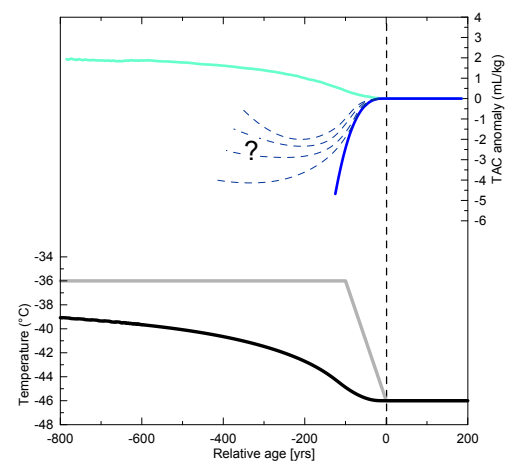

Figure 11. Modeled behavior of TAC for an idealized DO event with a $10^{\circ} \mathrm{C}$ linear surface warming during 100 years after the onset of the event. At the bottom, in grey, the assumed surface temperature and in black the temperature at bubble close-off depth. At the top, in turquoise, the TAC model output for steady-state firnification conditions (Eq. 11). Blue: the transient firnification model (Schwander et al., 1997) TAC output for a constant bubble close-off time. Dashed lines indicate the range of measured TAC anomalies.

DO events. Moreover, when comparing $\delta^{18} \mathrm{O}_{\text {ice }}$ in the ice matrix and a direct temperature-related signal in TAC, the uncertainty in the ice-age-gas-age difference has to be taken into account. Therefore, in the following we compare the TAC behavior to other proxies only on the same age scales.

To figure out how the TAC reacts in general to DO event warmings, we calculated a stack of TAC variations during
DO events and compared it to other gas phase parameters. Since the TAC seems to react in the time window where $\mathrm{CH}_{4}$ also shows changes, we stacked the TAC around the $\mathrm{CH}_{4}$ onsets. For this we defined a criterion for the rise in $\mathrm{CH}_{4}$. The analytical error in the $\mathrm{CH}_{4}$ data is 5.9 ppbv (Baumgartner et al., 2014). The start of the $\mathrm{CH}_{4}$ increase was defined by Baumgartner et al. (2014) in the middle between the first two data points during the onset of stadial-interstadial transitions which did not agree within their $3 \sigma$ uncertainty anymore. We used the same definition and translated the depth values on the AICC2012 gas age scale. Additionally, we defined the onset for DO 3 and 22 by applying only a $2 \sigma$ criterion, since with $3 \sigma$, no onset could be defined. These criteria give the onsets given in Table 4, except for DO 2 and 25, for which the onset could not be defined. The same stacking analysis was performed for $\delta^{15} \mathrm{~N}$ (Kindler et al., 2014), indicating temperature gradients across the firn column caused by rapid warming at the surface. The TAC (this study) and the $\delta^{15} \mathrm{~N}$ time series from Kindler et al. (2014) were then cut out in age windows +400 and -1000 years around the DO onsets in $\mathrm{CH}_{4}$. For each window we subtracted the mean value over this time span to remove the long-term trend in the data. Note that we ignored the temperature effect on pore volume as discussed in Sect. 4.1, as this effect is small (Fig. 5) and does not occur in the gas itself but acts on the firn matrix. Due to gas-age-ice-age difference, the latter process is, therefore, not in phase with changes in temperature but affects TAC several hundred years later. The resulting data 
Table 4. Timing of the DO events and related features. The time value in $\delta^{18} \mathrm{O}_{\text {ice }}$ denotes the maximum of the rise in $\delta^{18} \mathrm{O}_{\text {ice }}$ on the AICC2012 ice age scale, determined visually. The time point in TAC is the time of the minimum, found with the method described in Sect. 4.3.2. On average the $\delta^{18} \mathrm{O}_{\text {ice }}$ rise is younger by $-12 \pm 290$ years with a median of -10 years on the AICC2012 age scale. The corresponding values on the sso9sea06bm ice age scale and the gas age scale published by Kindler et al. (2014) are also shown in the second block of the table. On average the $\delta^{18} \mathrm{O}_{\text {ice }}$ rise is older by $111 \pm 233$ years with a median of 140 years on these age scales. The third block shows the timing of the onset in $\mathrm{CH}_{4}$ used for the stacking in Fig. 10a on the AICC2012 gas age scale (Veres et al., 2013). In the forth block, the onsets in bubble close-off temperature $T_{\text {cod }}$ used for the stacking in Fig. 10b on the AICC2012 ice age scale are displayed.

\begin{tabular}{|c|c|c|c|c|c|c|c|c|}
\hline DO & $\begin{array}{r}\delta^{18} \mathrm{O}_{\text {ice }} \\
(\mathrm{AICC} 2012 \text { ice })\end{array}$ & $\begin{array}{r}\text { TAC } \\
(\text { AICC2012 gas) }\end{array}$ & $\begin{array}{r}\text { Diff. } \\
(\mathrm{yr})\end{array}$ & $\begin{array}{r}\delta^{18} \mathrm{O}_{\text {ice }} \\
\text { ss09sea06bm }\end{array}$ & $\begin{array}{r}\text { TAC } \\
\text { (Kindler gas) }\end{array}$ & $\begin{array}{r}\text { Diff. } \\
\text { (yr) }\end{array}$ & $\begin{array}{r}\mathrm{CH}_{4} \\
(\mathrm{AICC} 2012 \text { gas) }\end{array}$ & $\begin{array}{r}\mathrm{T}_{\text {cod }} \\
\text { (AICC2012 ice) }\end{array}$ \\
\hline PB & 11570 & 11580 & -10 & 11464 & 11390 & 74 & - & - \\
\hline $\mathrm{BA}$ & 14551 & 14560 & -9 & 14534 & 14439 & 95 & 14904 & 15780 \\
\hline 2 & 23251 & 23600 & -349 & 22669 & 22569 & 100 & - & 22100 \\
\hline 3 & 27691 & 27820 & -129 & 27364 & 27264 & 100 & 28117 & 29060 \\
\hline 4 & 28751 & 28790 & -39 & 28462 & 28303 & 158 & 29280 & 30440 \\
\hline 5 & 32410 & 32660 & -250 & 32217 & 32064 & 153 & 33062 & 33740 \\
\hline 6 & 33630 & 33810 & -180 & 33519 & 33384 & 134 & 34246 & 34960 \\
\hline 7 & 35390 & 35480 & -90 & 35335 & 35199 & 136 & 35918 & 36880 \\
\hline 8 & - & - & - & - & - & - & 38303 & 40120 \\
\hline 9 & - & - & - & - & - & - & 40273 & 41120 \\
\hline 10 & 41391 & 41220 & 171 & 41728 & 41560 & 168 & 41521 & 42580 \\
\hline 11 & 43270 & 43140 & 130 & 43657 & 43459 & 198 & 43445 & 44560 \\
\hline 12 & 46789 & 46610 & 179 & 47355 & 47215 & 140 & 46851 & 47960 \\
\hline 13 & 49210 & 50020 & -810 & 49782 & 50504 & -722 & 49341 & 50120 \\
\hline 14 & 54151 & 53880 & 271 & 55056 & 54745 & 311 & 54294 & 55200 \\
\hline 15 & 55651 & 55440 & 211 & 56516 & 56314 & 202 & 55837 & 56740 \\
\hline 16 & - & - & - & - & - & - & 58106 & 58980 \\
\hline 17 & - & - & - & - & - & - & 59086 & - \\
\hline 18 & - & - & - & - & - & - & 64059 & 65520 \\
\hline 19 & 72087 & 71940 & 147 & 72957 & 72815 & 142 & 72095 & 73320 \\
\hline 20 & - & - & - & - & - & - & 75860 & 76820 \\
\hline 21 & 84130 & 83570 & 560 & 85421 & 84925 & 496 & 84101 & 84780 \\
\hline 22 & - & - & - & - & - & - & 89402 & 90040 \\
\hline 23 & - & - & - & - & - & - & 101844 & 102320 \\
\hline 24 & 105747 & 105760 & -13 & 108882 & 108886 & -4 & 106065 & 10660 \\
\hline \multirow[t]{3}{*}{25} & - & - & - & - & - & - & - & 113240 \\
\hline & & Average & $-12 \pm 290$ & & Average & $111 \pm 233$ & & \\
\hline & & Median & -10 & & Median & 140 & & \\
\hline
\end{tabular}

were then stacked and for each of them - the $\mathrm{CH}_{4}$, the TAC, and $\delta^{15} \mathrm{~N}$ data - a spline with a cutoff period of 200 years was calculated. The result is displayed in the left panel of Fig. 10. Relative to $\mathrm{CH}_{4}$, the measured TAC decrease starts around 100 years earlier. Within the error, $\delta^{15} \mathrm{~N}$ starts to increase synchronously with TAC. This 100 -year lag of $\mathrm{CH}_{4}$ to temperature is somewhat more than the $25-70 \pm 25$ years calculated for DO events in Marine Isotope Stage 3 in previous studies (Huber et al., 2006) and clearly more than the $4.5_{-24}^{+21}$ years for the Bølling-Allerød interstadial (BA) calculated in Rosen et al. (2014). This difference may partly be attributed to the different methods used in the various publications to detect the onset in the $\mathrm{CH}_{4}$ rise and/or may be specific to the BA warming. Note that the stacked TAC data show a two-step decrease that lasts for several hundred years. When the $\delta^{15} \mathrm{~N}$ signal reaches its maximum, TAC is still decreasing; shortly before the $\delta^{15} \mathrm{~N}$ stabilizes, the TAC slightly rises and then drops in a second step to lower values than before the event.

The total amplitude of the TAC response in Fig. 10a is $-4.7 \pm 0.7 \mathrm{~mL} \mathrm{~kg}^{-1}$. Using Eq. (1) with all parameters but the temperature fixed, we can calculate the expected physical TAC response according to the ideal gas law (Fig. 10b). The temperature influencing the TAC is the bubble close-off temperature, as derived by Kindler et al. (2014) using a heat transport model with the surface temperature determined by $\delta^{15} \mathrm{~N}$ thermodiffusion thermometry. To get an average behavior of bubble close-off temperature, we also stacked this modeled firn temperature at bubble close-off for the DO events in windows of +200 to -800 years relative to the onset in close-off temperature (see Table 4). We then calculated the mean over 50 -year intervals from +175 to -775 year around the starting points of the temperature increase at bubble close-off (red points in Fig. 10b). The starting points were defined as the onset in bubble close-off temperature 
provided by Kindler et al. (2014) on a depth scale, translated to the AICC2012 ice age scale. With a starting temperature and TAC of $227.15 \mathrm{~K}_{\text {and }} 90 \mathrm{~mL} \mathrm{~kg}^{-1}$, respectively, we computed the expected TAC response (blue crosses in Fig. 10b). Also shown in Fig. 10b are the measured TAC values on ice age scale for comparison with the modeled TAC and the temperature at the surface. The calculated amplitude of the direct temperature effect through the ideal gas law (number density of molecules per volume) at bubble closeoff is $1.4 \mathrm{~mL} \mathrm{~kg}^{-1}$, which is only about a third of the measured one. The amplitude difference indicates that other effects than the temperature at bubble close-off influence TAC on short timescales and especially during the second step of the TAC decrease, where in situ gas temperature changes are already quite small.

One possibility of explaining the larger TAC amplitude than expected from the direct temperature effect could be cooccurring changes in surface pressure, for example related to synoptic pressure pattern changes related to DO events. To explain the full amplitude in DO event TAC changes, however, a pressure decrease at the NGRIP site of around $17 \mathrm{hPa}$ would be required during interstadial warmings, potentially related to a northward shift of North Atlantic storm tracks (Kageyama et al., 2009) connected to a drastic reduction of sea ice during DO events which would also lead to a lowering of synoptic pressure over Greenland (Zhang et al., 2014). However, compared to currently observed spatial gradients in mean annual sea level pressure over the North Atlantic, the size of this effect appears too large and, moreover, should occur synchronously with the onset of the DO events and thus is unlikely to explain the TAC changes in later stages of the DO events. In contrast, a transient effect of changes in firnification, hence pore volume, during Greenland interstadials appears more likely to explain our observations. We suggest that such an effect can be induced by the rapidly increasing accumulation rate at the onset of the DO event. This leads to a higher load and thus enhanced deformation of the snow grains at depth at a time when the temperature in the firn column is still cold. A simple transient firnification model experiment (Sect. 4.3.3) supports this hypothesis by reducing TAC by several milliliters per kilogram as in our observations. In the following we attempt to quantify an upper limit of this transient firnification effect using a standard firnification model (Schwander et al., 1997).

\subsubsection{Transient firnification model experiment}

Empirical equations for estimating bubble close-off densities and bubble close-off depths have been derived for steadystate conditions (Martinerie et al., 1992, 1994). However, especially at the beginning of a DO event the firn layer is far from being in a steady state condition. Fast artificial densification experiments of snow by applying high pressures resulted in very low TAC compared to natural firnification (B. Stauffer, personal communication, 2015). The reason for low TAC in artificially densified ice is most likely that, due to the extremely high densification rate, there is not enough time to form spherical cavities, which are a result of minimizing surface energy by slow mass redeposition through vapor diffusion. At the beginning of a DO event, accumulation increases in a step-like fashion, causing (less drastically but analogous to the artificial experiments) additional pressure in the bubble close-off zone by the increasing load of snow. We therefore expect a pore volume reduction and expulsion of air from the firn, yielding to lower TAC compared to steady-state conditions.

We estimate the upper limit of this effect by assuming that for some 140 annual layers above the firn-ice transition in the firnification model, the time required to reach bubble closeoff remains unchanged after a transition to a DO event. This assumption is based on the fact that the temperature at the depth of bubble close-off remains near the cold state during the first 140 years of a DO event (less than $20 \%$ temperature response compared to the surface temperature change; Fig. 10) and on the hypothesis that time is more important for finalizing the bubble close-off than the additional hydrostatic pressure.

We have used a standard dynamic firn densification model (Schwander et al., 1997) to calculate this upper limit for a typical DO event. In addition to computing the time and depth where the steady-state close-off density is reached (as in the normal usage of the model) the model provides the density that a firn layer reaches after a certain number of years. This number of years was set to the duration needed to reach close-off under interstadial conditions. Under the abovementioned assumption of an initially constant duration to reach close-off, this density reflects the true close-off density and corresponding TAC better than values obtained for steady-state stadial conditions. Stadial temperature is set to $-46^{\circ} \mathrm{C}$ and the ice accumulation rate to $0.05 \mathrm{~m} \mathrm{a}^{-1}$. At the beginning of the simulated DO event, we increase the temperature from -46 to $-36^{\circ} \mathrm{C}$ and the ice accumulation rate from 0.05 to $0.1 \mathrm{~m} \mathrm{yr}^{-1}$ within 100 years, based on the model data by Kindler et al. (2014). The resulting TAC of the simulation is shown in Fig. 11. We interpret the resulting decrease in TAC as the upper limit scenario for the first 140-years of a DO event. The real effect might be smaller. Later, when the temperature at the firn-ice transition increases further, TAC will slowly approach the new equilibrium value. As there exists no physical model describing this dynamic behavior of densification and bubble close-off to date, we cannot provide a more precise modeled evolution of TAC during a DO event, but the decrease in TAC as observed in the NGRIP ice core seems to be compatible with the simulation.

\section{Conclusions}

We present the first high-resolution TAC record from the Greenland NGRIP ice core covering the last $120 \mathrm{kyr}$. In line 
with previous studies in Antarctica (Raynaud et al., 2007; Lipenkov et al., 2011), we find the low-frequency variations to depend on local summer insolation and thus the orbital parameters. Those effects act on the firn matrix controlling the pore volume during bubble close-off and, thus, operate on the ice age scale, (e.g. Raynaud et al., 2007; Bender, 2002), although the underlying processes are not yet understood. Additionally, in steady state, the pore volume is known to correlate with firn temperature (Martinerie et al., 1992), which is also an ice property leading to TAC changes. Our study shows that this temperature effect imprinted on pore volume during densification in steady state is small compared to the insolation effect operating at the surface and also small compared to a direct temperature effect on TAC imposed by the change in density of the gas during bubble enclosure that we clearly observe during DO events.

Comparison of $\delta^{15} \mathrm{~N}, \mathrm{CH}_{4}$ and TAC, all on the gas age scale, provides evidence that surface temperature warming, or an effect synchronous with surface warming, has a direct imprint on the TAC. The immediate decrease in TAC at an onset of a DO event could have two possible sources according to the ideal gas law: decreasing air pressure or less amount of substance per volume due to rising temperature. However, both effects appear to be too small to explain the measured TAC decline. Large changes in the height of the ice sheet are ruled out for such very short-term variations as the TAC change occurs immediately with the DO event warming, while the ice sheet response would be slow and delayed. However, the increasing accumulation rate during DO events leads to an increase in firn thickness of several tens of meters, which, through the additional weight on the firn column, leads to a temporarily enhanced densification. This could reduce TAC for several centuries after the onset of the DO event. After 500-1000 years, the firn column reaches a new equilibrium with ambient temperature, accumulation and pore volume, and TAC reaches its steady-state value again.

With the TAC signal being influenced by effects on the ice age and gas age scale, this also limits the precision of deriving orbital timescales from TAC for Greenland ice cores, which experience the rapid millennial scale DO variability which is absent for Antarctic ice cores.

\section{Data availability}

The NGRIP TAC data are available at https://www.ncdc. noaa.gov/paleo/study/20569.

Acknowledgements. Continuing support by the Swiss National Science Foundation for ice core research at the University of Bern is gratefully acknowledged. NGRIP is coordinated by the Department of Geophysics at the Niels Bohr Institute for Astronomy, Physics and Geophysics, University of Copenhagen. It is supported by Funding Agencies in Denmark (SHF), Belgium (FNRS-CFB),
France (IPEV and INSU/CNRS), Germany (AWI), Iceland (RannIs), Japan (MEXT), Sweden (SPRS), Switzerland (SNF) and the United States of America (NSF, Office of Polar Programs). We thank J. Freitag for fruitful discussion on firnification and bubble enclosure processes.

Edited by: C. Barbante

Reviewed by: two anonymous referees

\section{References}

Baumgartner, M.: Bipolar reconstructions of atmospheric methane and nitrous oxide during the las glacial-interglaccial cycle, $\mathrm{PhD}$ thesis, Physics Institute, University of Bern, Switzerland, 194 pp., 2013.

Baumgartner, M., Schilt, A., Eicher, O., Schmitt, J., Schwander, J., Spahni, R., Fischer, H., and Stocker, T. F.: High-resolution interpolar difference of atmospheric methane around the Last Glacial Maximum, Biogeosciences, 9, 3961-3977, doi:10.5194/bg-93961-2012, 2012.

Baumgartner, M., Kindler, P., Eicher, O., Floch, G., Schilt, A., Schwander, J., Spahni, R., Capron, E., Chappellaz, J., Leuenberger, M., Fischer, H., and Stocker, T. F.: NGRIP $\mathrm{CH}_{4}$ concentration from 120 to $10 \mathrm{kyr}$ before present and its relation to a $\delta^{15} \mathrm{~N}$ temperature reconstruction from the same ice core, Clim. Past, 10, 903-920, doi:10.5194/cp-10-903-2014, 2014.

Bender, M. L.: Orbital tuning chronology for the Vostok climate record supported by trapped gas composition, Earth Planet. Sc. Lett., 204, 275-289, 2002.

Born, A. and Nisancioglu, K. H.: Melting of Northern Greenland during the last interglaciation, The Cryosphere, 6, 1239-1250, doi:10.5194/tc-6-1239-2012, 2012.

Dahl-Jensen, D., Gundestrup, N., Keller, K., Johnsen, S., Gogineni, S., Allen, C., Chuah, C., Miller, H., Kipfstuhl, S., and Wassington, E.: A search in north Greenland for a new ice-core drill site, J. Glaciol., 43, 300-306, 1997.

Enting, I. G.: On the Use of Smoothing Splines to Filter $\mathrm{CO}_{2}$ Data, J. Geophys. Res.-Atmos., 92, 10977-10984, 1987.

Fischer, H., Siggaard-Andersen, M.-L., Ruth, U., Röthlisberger, R., and Wolff, E.: Glacial/interglacial changes in mineral dust and sea-salt records in polar ice cores: Sources, transport, and deposition, Rev. Geophys., 45, rG1002, doi:10.1029/2005RG000192, 2007.

Flückiger, J., Blunier, T., Stauffer, B., Chappellaz, J., Spahni, R., Kawamura, K., Schwander, J., Stocker, T., and Dahl-Jensen, D.: $\mathrm{N}_{2} \mathrm{O}$ and $\mathrm{CH}_{4}$ variations during the last glacial epoch: Insight into global processes, Global Biogeochem. Cy., 18, doi:10.1029/2003GB002122, 2004.

Freitag, J., Kipfstuhl, S., Laepple, T., and Wilhelms, F.: Impuritycontrolled densification: a new model for stratified polar firn, J. Glaciol., 59, 1163-1169, doi:10.3189/2013JoG13J042, 2013.

Grinsted, A., Moore, J. C., and Jevrejeva, S.: Application of the cross wavelet transform and wavelet coherence to geophysical time series, Nonlin. Processes Geophys., 11, 561-566, doi:10.5194/npg-11-561-2004, 2004.

Huber, C., Leuenberger, M., Spahni, R., Flückiger, J., Schwander, J., Stocker, T. F., Johnsen, S., Landais, A., and Jouzel, J.: Isotope calibrated Greenland temperature record over Marine Iso- 
tope Stage 3 and its relation to $\mathrm{CH}_{4}$, Earth Planet. Sc. Lett., 243, 504-519, 2006.

Hutterli, M., Schneebeli, M., Freitag, J., Kipfstuhl, J., and Röthlisberger, R.: Impact of local insolation on snow metamorphism and ice core records, Low Temperature Science, 68, 223-232, 2009.

Hörhold, M., Laepple, T., Freitag, J., Bigler, M., Fischer, H., and Kipfstuhl, S.: On the impact of impurities on the densification of polar firn, Earth Planet. Sc. Lett., 325-326, 93-99, doi:10.1016/j.eps1.2011.12.022, 2012.

Kageyama, M., Mignot, J., Swingedouw, D., Marzin, C., Alkama, R., and Marti, O.: Glacial climate sensitivity to different states of the Atlantic Meridional Overturning Circulation: results from the IPSL model, Clim. Past, 5, 551-570, doi:10.5194/cp-5-5512009, 2009.

Kindler, P., Guillevic, M., Baumgartner, M., Schwander, J., Landais, A., and Leuenberger, M.: Temperature reconstruction from 10 to 120 kyr b2k from the NGRIP ice core, Clim. Past, 10, 887-902, doi:10.5194/cp-10-887-2014, 2014.

Krinner, G., Raynaud, D., Doutriaux, C., and Dang, H.: Simulations of the Last Glacial Maximum ice sheet surface climate: Implications for the interpretation of ice core air content, J. Geophys. Res.-Atmos., 105, 2059-2070, 2000.

Landais, A., Masson-Delmotte, V., Capron, E., Langebroek, P. M., Bakker, P., Stone, E. J., Merz, N., Raible, C. C., Fischer, H., Orsi, A., Prié, F., Vinther, B., and Dahl-Jensen, D.: How warm was Greenland during the last interglacial period?, Clim. Past Discuss., doi:10.5194/cp-2016-28, in review, 2016.

Lang, C., Leuenberger, M., Schwander, J., and Johnsen, S.: $16^{\circ} \mathrm{C}$ Rapid Temperature Variation in Central Greenland 70,000 Years Ago, Science, 286, 934-937, doi:10.1126/science.286.5441.934, 1999.

Lipenkov, V., Raynaud, D., Loutre, M., and Duval, P.: On the potential of coupling air content and $\mathrm{O}_{2} / \mathrm{N}_{2}$ from trapped air for establishing an ice core chronology tuned on local insolation, Quaternary Sci. Rev., 30, 3280-3289, 2011.

Lorius, C., Raynaud, D., and Dolle, L.: Densité de la glace et Étude des gaz en profondeur dans un glacier antarctique, Tellus, 20, 449-460, 1968.

Martinerie, P., Raynaud, D., Etheridge, D. M., Barnola, J. M., and Mazaudier, D.: Physical and climatic parameters which influence the air content in polar ice, Earth Planet. Sc. Lett., 112, 1-13, 1992.

Martinerie, P., Lipenkov, V. Y., Raynaud, D., Chappellaz, J., Barkov, N. I., and Lorius, C.: Air content paleo record in the Vostok ice core (Antarctica): A mixed record of climatic and glaciological parameters, J. Geophys. Res., 99, 10565-10576, 1994.

NEEM community members: Eemian interglacial reconstructed from a Greenland folded ice core, Nature, 493, 489-494, doi:10.1038/nature11789, 2013.

NGRIP Project Members: High-resolution record of Northern Hemisphere climate extending into the last interglacial period, Nature, 431, 147-151, doi:10.1038/nature02805, 2004.

Parrenin, F., Barnola, J.-M., Beer, J., Blunier, T., Castellano, E., Chappellaz, J., Dreyfus, G., Fischer, H., Fujita, S., Jouzel, J., Kawamura, K., Lemieux-Dudon, B., Loulergue, L., MassonDelmotte, V., Narcisi, B., Petit, J.-R., Raisbeck, G., Raynaud, D., Ruth, U., Schwander, J., Severi, M., Spahni, R., Steffensen, J. P., Svensson, A., Udisti, R., Waelbroeck, C., and Wolff, E.: The
EDC3 chronology for the EPICA Dome C ice core, Clim. Past, 3, 485-497, doi:10.5194/cp-3-485-2007, 2007.

Raynaud, D. and Lebel, B.: Total gas content and surface elevation of polar ice sheets, Nature, 281, 289-291, 1979.

Raynaud, D. and Lorius, C.: Climatic implications of Total Gas Content in Ice at Camp Century, Nature, 243, 283-284, 1973.

Raynaud, D., Chappellaz, J., Ritz, C., and Martinerie, P.: Air content along the Greenland Ice Core Project core: A record of surface climatic parameters and elevation in Central Greenland, J. Geophys. Res., 102, 26607-26613, 1997.

Raynaud, D., Lipenkov, V., Lemieux-Dudon, B., Duval, P., Loutre, M.-F., and Lhomme, N.: The local insolation signature of air content in Antarctic ice. A new step toward an absolute dating of ice records, Earth Planet. Sc. Lett., 261, 337-349, doi:10.1016/j.eps1.2007.06.025, 2007.

Rosen, J. L., Brook, E. J., Severinghaus, J. P., Blunier, T., Mitchell, L. E., Lee, J. E., Edwards, J. S., and Gkinis, V.: An ice core record of near-synchronous global climate changes at the Bolling transition, Nat. Geosci., 7, 459-463, doi:10.1038/ngeo2147, 2014.

Ruth, U.: Dust concentration in the NGRIP ice core, doi:10.1594/PANGAEA.587836, 2007.

Schilt, A., Baumgartner, M., Schwander, J., Buiron, D., Capron, E., Chappellaz, J., Loulergue, L., Schüpbach, S., Spahni, R., Fischer, H., and Stocker, T. F.: Atmospheric nitrous oxide during the last 140,000 years, Earth Planet. Sc. Lett., 300, 33-43, 2010.

Schilt, A., Baumgartner, M., Eicher, O., Chappellaz, J., Schwander, J., Fischer, H., and Stocker, T.: The response of atmospheric nitrous oxide to climate variations during the last glacial period, Geophys. Res. Lett., 40, 1888-1893, doi:10.1002/grl.50380, 2013.

Schmitt, J., Schneider, R., and Fischer, H.: A sublimation technique for high-precision measurements of $\delta^{13} \mathrm{CO}_{2}$ and mixing ratios of $\mathrm{CO}_{2}$ and $\mathrm{N}_{2} \mathrm{O}$ from air trapped in ice cores, Atmos. Meas. Tech., 4, 1445-1461, doi:10.5194/amt-4-1445-2011, 2011.

Schmitt, J., Seth, B., Bock, M., and Fischer, H.: Online technique for isotope and mixing ratios of $\mathrm{CH}_{4}, \mathrm{~N}_{2} \mathrm{O}$, Xe and mixing ratios of organic trace gases on a single ice core sample, Atmos. Meas. Tech., 7, 2645-2665, doi:10.5194/amt-7-2645-2014, 2014.

Schwander, J., Sowers, T., Barnola, J. M., Blunier, T., Malaizé, B., and Fuchs, A.: Age scale of the air in the Summit ice: Implication for glacial-interglacial temperature change, J. Geophys. Res., 102, 19483-19494, 1997.

Seierstad, I. K., Abbott, P. M., Bigler, M., Blunier, T., Bourne, A. J., Brook, E., Buchardt, S. L., Buizert, C., Clausen, H. B., Cook, E., Dahl-Jensen, D., Davies, S. M., Guillevic, M., Johnsen, S. J., Pedersen, D. S., Popp, T. J., Rasmussen, S. O., Severinghaus, J. P., Svensson, A., and Vinther, B. M.: Consistently dated records from the Greenland GRIP, GISP2 and NGRIP ice cores for the past $104 \mathrm{ka}$ reveal regional millennial-scale delta ${ }^{18} \mathrm{O}$ gradients with possible Heinrich event imprint, Quaternary Sci. Rev., 106, 29-46, doi:10.1016/j.quascirev.2014.10.032, 2014.

Severinghaus, J. P. and Brook, E. J.: Abrupt Climate Change at the End of the Last Glacial Period Inferred from Trapped Air in Polar Ice, Science, 286, 930-934, doi:10.1126/science.286.5441.930, 1999.

Suwa, M. and Bender, M. L.: $\mathrm{O}_{2} / \mathrm{N}_{2}$ ratios of occluded air in the GISP2 ice core, J. Geophys. Res.-Atmos., 113, d11119, doi:10.1029/2007JD009589, 2008. 
Veres, D., Bazin, L., Landais, A., Toyé Mahamadou Kele, H., Lemieux-Dudon, B., Parrenin, F., Martinerie, P., Blayo, E., Blunier, T., Capron, E., Chappellaz, J., Rasmussen, S. O., Severi, M., Svensson, A., Vinther, B., and Wolff, E. W.: The Antarctic ice core chronology (AICC2012): an optimized multi-parameter and multi-site dating approach for the last 120 thousand years, Clim. Past, 9, 1733-1748, doi:10.5194/cp-9-1733-2013, 2013.
Zhang, X., Lohmann, G., Knorr, G., and Purcell, C.: Abrupt glacial climate shifts controlled by ice sheet changes, Nature, 512, 290294, 2014. 